\title{
Resilience: A necessity to manage change in organizations
}

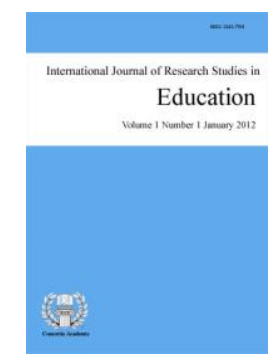

Carlos, Catherine Nicca M.

University of Santo Tomas, Philippines (cmcarlos@ust.edu.ph)

Tan, Emily B.

University of Santo Tomas, Philippines (emilybtan@yahoo.com)

\section{Abstract}

As the world continues to battle the global pandemic, organizations face a lot of challenges, most especially that which shoves them to a certain change. With what is at hand, they must continue to strive for progress even amidst adversities. An important element of Organizational Development is change management - a systematic approach aimed to arise with strategies and methods that will be enforced to effect change and be able to adapt to it efficiently (SIGC, 2016). Adapting and managing change is a challenge that calls for organizational resilience. In this paper, the significance of resilience in organizations is emphasized. Organizational resilience models are identified and briefly described to guide would-be employee development programs. This paper considers organizational resilience as contributive not just to organizational structure development but also in building a more positive organizational culture.

Keywords: resilience, organization resilience, change management, organizations, organizational development 


\title{
Resilience: A necessity to manage change in organizations
}

\section{Introduction}

\author{
"Change is the only constant in life. One's ability to adapt to those changes will determine your \\ success in life." - Benjamin Franklin
}

Change is certain. It is a constant force that we are confronted with from time to time. This claim is supported as we have witnessed how the global pandemic has transformed the way we live, interact and thrive. To push further, we were just trying to hold our gates up against a virus, when calamity, one after another knocked us down. Who would have thought that even with what seems to be an insurmountable amount of effort of preparation was not enough? Hence, one may assume that change is not something we just face, but something we overcome together.

The same is true most especially in organizations, which must continually strive to progress even amidst adversities. An important element of Organizational Development is change management - a systematic approach to how organizational goals, values, processes, and the like are moved to a certain shift of transformation (SIGC, 2016). It is aimed to arise with strategies and methods that will be enforced to effect change and be able to adapt to it efficiently (SIGC, 2016). Change management programs in organizations would be more effective if members of the whole team would develop the so-called, Resilience.

\section{Resilience in an organization}

Resilience, aside from being an attitude, is also used to describe an organization. The term "organizational resilience" means the "maintenance of positive adjustment under challenging conditions such that an organization emerges from those conditions strengthened and more resourceful" (Vogus \& Sutcliffe, 2007). It is also conceptualized as "the ability to develop capabilities and capacities necessary to thrive despite challenges, as well as to bounce back from adverse situations" (Lengnick-Hall et al., 2011). Noticeably, resilience is imperative in making sure organizations collectively survive.

With most of the work's nature of being volatile, resilience is vital for employees to perform effectively especially in challenging and demanding situations (Fredrickson, Tugade, Waugh, \& Larkin, 2003). Coutu, 2002 \& Fredrickson, 2001, would say that team resilience gives a possibility to aid better performance and success. According to research, preparedness for change that leads to the resilience of employees is enhanced when employees are given persistent support and encouragement to be creative when dealing with it (Sundblad, Älgevik, Wanther, \& Lindmark, 2013). Therefore, if the goal is to thrive as an organization beyond the given undesirable situation, especially in unfortunate changes, resilience is the key. It is a prudent strategy in fostering quality of work as we move forward in the sustained pursuit of a common goal.

\section{Models of resilience as contributory to change management}

\subsection{The Johns Hopkins Model (Teng-Calleja et al., 2020)}

This model is a cyclical process highlighting the before (resistance), during or in the period of (recovery), and after a crisis or disaster (resilience). This model sees a continuum of interventions as a requirement to resilience-building to become sturdy amidst disasters (resistance), the capacity to function in normalcy again (recovery), and rebound after (resilience). The first stage in this model is Resistance. It is described as "the ability to resist or develop an immunity both psychological and behavioral against distress and dysfunction"

2 Consortia Academia Publishing (A partner of Network of Professional Researchers and Educators) 
(Nucifora et al., 2007 cited by Teng-Calleja et al., 2020). According to this model, resistance as a proactive stance (versus reactive stance) toward disaster preparedness is significant for inclusion. This stage includes initiatives to increase resilience before chaos happens, such as disaster training, and other programs that ideally receive ample support from the administration. The second stage is Resilience, which pertains to "the ability to rapidly and effectively rebound from psychological and/or behavioral perturbations." This stage includes strategies such as protocols to address the crisis as it happens and interventions in terms of mental health concerns in the post-disaster (individual or organization-based intervention). The third stage is Recovery which pertains to "the ability to recover psychologically and behaviorally, - and regain a sense of control after experiencing distress in the light of critical incidents." This stage suggests therapy for trauma victims and debriefing as possible interventions.

\subsection{Sense making (Weick, 1993, 1995)}

Sense making is a perspective that seeks to know how people literally make-sense of unexplainable circumstances and how they generate an order from confusion and what seems to be a chaotic situation (Weick, 1995). Maitlis et al. $(2014,2010)$ and Weick (1995) would say that in experiencing unexplainable situations, generally, the members of the organization search for answers by making sense of the prompts around them; This leads to grasping what has transpired. These sense making processes now change the views and practices of the individuals or organizations as well as how they plan to deal with the challenges encountered (Maitlis \& Christianson, 2014).

\subsection{Conservation of resources model (Hobfoll, 2011)}

Conservation of Resources' principle stresses that if individuals strive to acquire, maintain and secure the resources they value, then, they possess a "resilient" quality (Hobfoll, 2011). This means that a resilient individual obtains "resources to conduct the regulation of the self, their operation of social relations, and how they organize, behave and fit into the greater context of organizations and culture itself" (Hobfoll, 2011). An assumption of the theory of Conservation of Resources, based from Chen et al. (2015), is that "people are motivated and directed biologically, socially, cognitively and culturally to shepherd their resources to obtain, retain and protect their resource reservoirs" even when there is no danger or threat. Resilience, in the context of COR theory, is described as having the foresight and preparing enough resources to combat any mishap that may agitate the said resources. Stoverinks et al. (2018) names four team-level resources: "team potency, mental models of teamwork, team capacity to improvise, and team psychological safety." Additionally, they would define these resources as follows:

Team potency is a team's confidence that it can resolve and confront any encountered difficult task or demanding job successfully. Mental models of teamwork describe "team members' knowledge of roles, responsibilities, and interaction patterns and familiarity with one another's knowledge, skills, and preferences"; team capacity to improvise or adjust to demands carefully while emerging quickly and effectively something which is innovative out of the existing resources; and team psychological safety as "a shared belief that a team is safe to take interpersonal risks."

\subsection{What then is the relationship of the conservation of resources theory with the so-called "team resilience"?}

Morgan et al. (2013) describes team resilience as one that comprises a "process whereby team members use their individual and collective resources to positively adapt when experiencing adversity." Individual members of a certain team possess not just separate but also social resources because of their shared interactions. This contributes, then, to their collective capacity to adapt constructively to adverse events and even to the possible results of negative stressors they collectively encounter. The mentioned resources build in a team the capacity to harmonize their actions in the present adverse situation and create a shared meaning of the situation. 
In building resilient teams, what matters is how the members make sense of the critical events and arrange their team resources so that the team can go about performing its tasks (Degbey \& Einola, 2019). When facing unfortunate situations, a team initially expresses negative reactions and emotions. For instance, their 'resource investment' (such as team psychological positive emotions, team potency, and team capacity improvise Stoverinks et al., 2018) is not well-established. In these cases, they are drawn towards misfocus and may find it difficult to respond accordingly. Sense making, then, aids a better understanding of the present difficulty while at the same time paving the way to appropriate responses and wiser alternatives (Degbey \& Einola, 2019).

Additionally, elevating positive emotions is also a vital factor to develop team resilience (Morgan et al., 2015). Self-reflection could help them actively identify the roots of why the adverse situations happen at present, to be keener with signals, and prepare for realistic plans (Alliger et al., 2015). Through this, learning from the adverse situation, which changed the team almost holistically, will be ensured (Alliger et al., 2015). In this way as well, the so-called "resilient" resources make a robust foundation in an organization.

\subsection{Vulnerability-resilience model (Faulkner et al., 2020)}

According to the proponents, this model primarily aims to connect the two concepts of vulnerability and resilience, which normally is ignored in planning theory and practice. Most literature treats these two concepts in a "codependent dualism model" whereby vulnerability is seen as opposite to resilience (Faulkner et al., 2020). So often are these two concepts taken exclusively from each other. Hence, the proponents stitch literature that focus either on resilience or vulnerability alone. The model highlights four components namely: (1) "exposure (relating to pre-shock attributes), (2) sensitivity (relating to negative impacts caused by shock), (3) capacity of response (relating to pre-shock attributes), and (4) adaptive capacity (relating to positive responses to shock)" that which intellectualizes vulnerability and resilience in a holistic approach.

According to the proponents, this model is positioned towards exposure and/or "capacity of response", and sensitivity and/or "adaptive capacity." Nonetheless, these four components need to be interconnected to understand their practical implications. The proponents argue that "resilience is essentially a component of vulnerability since shocks cause vulnerability in the first instance" (Faulkner et al., 2020, p.11). They sought the potential interconnections between and among the four components in order to prove that resilience and vulnerability can be explored side by side with each other. Taking that into consideration, they argue now that "it is the resilience components of the capacity of response and adaptive capacity that mitigate the impact of a shock, only once it has taken place."

One argument after the other, the proponents concluded that it is, then, possible for both vulnerability and resilience to occur at the same time, in certain places. This is due to the so-called "place-based attributes" as well as leadership and adaptive capacity. Diverse economic base and governance institutions are also factors to look into, in balancing vulnerability and resilience. Therefore, it is safe to say that this model represents the multifaceted and complex process of their correlation.

\section{A Proposed Resilience Funnel Model}

A conceived model of Catherine Nicca M. Carlos (2021) for a possible contribution in building organizational resilience in the face of change management. In perception, there are three vital elements in developing resilience both as an individual and as an organization. First is the experience. The endurance of an uncomfortable experience at the first time of encounter) aids a lot in learning to cope with the probability of encountering the same uncomfortable experience the second time. In this way, the organization will be able to prepare well for the next time they come across the same adversity. The second element is the individual's or an organizations' collective belief system and/or principles. Most organizations uphold a certain ideology. It may be an advocacy, a thrust, a value, or a spirituality. This is basically the reason why organizations would have a

4 Consortia Academia Publishing (A partner of Network of Professional Researchers and Educators) 
mission, vision, and goals. In facing adversities, an organization can be resilient when every member visualizes each of them holding on and believing in that one and common belief system or principle. With this kind of attitude and mindset, an organization thrives. And with this kind of persistence, an organization builds resilience. The third element is support, from which an organization finds itself in the process of continuous organizational development when it realizes that it still has a constant provision in the financial, social, psychological, and even moral aspects. How often have we seen an organization falter due to the absence of backing and assistance? Hence, it is contributory to the overall organizational resilience that they receive valued and continuous support. It boosts their self-assurance, especially in identifying their capacity to traverse adversity. When all these three extensive elements are congregated, the organization then journeys toward the depth of resilience to which it becomes adept.

\section{Implication}

To pursue Organizational Resilience is to hone an organizational culture that is more people-centered. As SIGC (2016) would claim: any intervention for Organizational Development must be people-centered, and unashamedly humanistic. Moreover, to effect change in the organization, the centrality must always be geared towards the benefit of the people and enacted by the people. Thus, Organizational Resilience develops every member of an organization to manage positively any sort of change and leads the whole team to display pliability, making the whole organization more stable. Realizing how the circumstances of today can 'rock our organizations' boat', this overlooked feature becomes inevitable. Organizational Resilience may also be injected into employee development programs, to be discussed as is, or be in an organizational development intervention such as team building and workshops. The models presented above can be an initial basis for conceptualizing these programs, with the hope that organizational resilience may immerse in an organizational culture: A culture that moves toward the so-called adhocracy - a corporate culture of an organization with collective capacity in adjusting to and being flexible with the constantly changing circumstances.

\section{Conclusion and future directions}

Resilience is a vital factor in change management especially when organizations would undergo development in these unpredictable times. The models presented here, namely: The Johns Hopkins resistance-resilience-recovery model; Integration of Sense making, Conservation of Resources, and Team Resilience; Vulnerability-Resilience Model could guide the organizational developers in planning how to shape organizational resilience in their respective teams. Additionally, the authors of this paper attempt to contribute to the existing models of resilience by creating their own model named as "The Resilience Funnel Model." This model names valuable elements - experience, basic principles, and support - that may aid in firming the resilience of an individual or culture of an organization. Researchers can apply qualitative research methods to assess how these models can work during this pandemic.

\section{References}

Alliger, G. M., Cerasoli, C. P., Tannenbaum, S.I., \& Vessey, W. B. (2015). Team resilience. Organizational Dynamics, 44, 176-184.

Cooke, F. L., Cooper, B., Bartram, T., Wang, J., \& Mei, H. (2016). Mapping the relationships between high-performance work systems, employee resilience, and engagement: A study of the banking industry in China. The International Journal of Human Resource Management, 1-22. https://doi.org/10.1080/09585192.2015.1137618

Coutu, D. L. (2002). How resilience works. Harvard Business Review, 80(5), 46-56.

Degbey, W. Y., \& Einola, K. (2020). Resilience in virtual teams: Developing the capacity to bounce back. Applied Psychology, 69, 1301-1337. https://doi.org/10.1111/apps.12220

Faulkner, J., Murphy, E. \& Scott, M. (2020): Developing a holistic 'vulnerability-resilience' model for local and regional development. European Planning Studies. https://doi.org10.1080/09654313.2020.1720612 
Carlos, C. N. M., \& Tan, E. B.

Fredrickson, B. L. (2001). The role of positive emotions in positive psychology: The broaden-and-build theory of positive emotions. American Psychologist, 56(3), 218-226.

Fredrickson, B. L., Tugade, M. M., Waugh, C. E., \& Larkin, G. R. (2003). What good are positive emotions in crisis? A prospective study of resilience and emotions following the terrorist attacks on the United States on September 11th, 2001. Journal of Personality and Social Psychology, 84(2), 365.

Hobfoll, S. E. (2011). Conservation of resource caravans and engaged settings. Journal of Occupational and Organizational Psychology, 84(1), 116-122.

Lengnick-Hall, C. A., Beck, T. E., \& Lengnick-Hall, M. L. (2011). Developing a capacity for organizational resilience through strategic human resource management. Human Resource Management Review, 21(3), 243-255.

Maitlis, S., \& Christianson, M. (2014). Sensemaking in organizations: Taking stock and moving forward. The Academy of Management Annals, 8(1), 57-125.

Morgan, P. B., Fletcher, D., \& Sarkar, M. (2013). Defining and characterizing team resilience in elite sport. Psychology of Sport and Exercise, 14(4), 549-559.

Nucifora, F., Langlieb, A., Siegal, E., Everly, G., \& Kaminsky, M. (2007). Building resistance, resilience, and recovery in the wake of school and workplace violence. Disaster Medicine and Public Health Preparedness, 1(1), 533-537. https://doi.org/10.1097/DMP.0b013e31814b98ae

Schaufeli, W. B., \& Bakker, A. B. (2010). Defining and measuring work engagement: Bringing clarity to the concept. In Work engagement: A handbook of essential theory and research (pp.10-24).

Schrodt, P. (2002). The relationship between organizational identification and organizational culture: Employee perceptions of culture and identification in a retail sales organization. Communication Studies, 53, 189-202.

Shrimati Indira Gandhi College. (2016). Organizational development. Sigc.edu. Retrieved from https://www.sigc.edu/department/mba/studymet/OrganisationDevelopment.pdf

Stoverink, A. C., Kirkman, B. L., Mistry, S., \& Rosen, B. (2018). Bouncing back together: Toward a theoretical model of work team resilience. Academy of Management Review, 1-69.

https://doi.org/10.5465/amr.2017.0005

Sundblad, F., Älgevik, T., Wanther, O., \& Lindmark, C. (2013). Leading change without resistance: A case study of Infrafone (pp. 1-14). Department of Project, Innovation and Entrepreneurship, Linköping University.

Teng-Calleja, M., Hechanova, M. R. M., Sabile, P. R., \& Villasanta, A. P. V. P. (2020). Building organization and employee resilience in disaster contexts. International Journal of Workplace Health Management, 13(4), 393-411. https://doi.org/10.1108/IJWHM-09-2019-0122

Vogus, T. J., \& Sutcliffe, K. (2007). Organizational Resilience: towards a theory and research agenda. 2007 International Conference on Systems, Man and Cybernetics Proceedings. https://doi.org/10.1109/ICSMC.2007.4414160

Weick, K. E. (1995). Sensemaking in organizations. Thousand Oaks, CA: Sage

6 Consortia Academia Publishing (A partner of Network of Professional Researchers and Educators) 